increase of the creatine phosphokinase (CPK) indicated myocarditis: CPK 2865 IU/l, CPKMB 288 IU/1. The CSF contained 24 white blood cells/ $\mathrm{mm}^{3}\left(24 \times 10^{6} / \mathrm{l}\right)(94 \%$ lymphocytes, $6 \%$ monocytes) with an increased level of protein: $1.50 \mathrm{~g} / 1$. A spirochaete began to grow in BSK II ${ }^{4}$ after the second week and a borrelia was identified. It had a diameter of $0.2 \mu \mathrm{m}$ and a length between 4 and $22 \mu \mathrm{m}$. By immunofluorescent assay high titres of IgG antibodies against Borrelia bugdorferri were detected in serum collected three weeks after the beginning of the illness $(1 / 160)$, and two months later $(1 / 320)$. The patient's phenotype was A2, B5, DR5. He received oral penicillin therapy (10 million U/day) for 15 days, and recovered.

For the first time in France a borrelia has been isolated from the CSF during Lyme disease. This isolation strengthens the role of borrelia as the aetiological agent responsible for the clinical signs in the acute phase of the disease. The late clinical manifestations could be secondary to an immune reaction triggered by the spirochaete, especially among patients who have the B cell alloantigen DR2. In France the carrier is unknown, but Ixodes ricinus occurs worldwide and its involvement is suspected.

Service de Cardiologie A, La Milétrie Chu Poitiers,

86021 Poitiers,

France

Institut Pasteur,

J MAZZONELLI

25 rue de Docteur Roux,

Paris 15ème,

France

\section{References}

1 Steere A C, Malawista S E. A cluster of arthritis in children and adults in Lyme, Connecticut. Arthritis Rheum 1976; 19: 824.

2 Steere A C, Robert L, Grodzicki R L, et al. The spirochetal etiology of Lyme disease. $N$ Engl J Med 1983; 308: 733-40.

3 Preac-Mursic V, Wilske B, Schierz G, Pfister H W, Einhaupl K. Repeated isolation of spirochetes from the cerebrospinal fluid of a patient with meningoradiculitis Bannwarth. Eur J Clin Microbiol 1984; 3: 564-5.

4 Barbour A. Isolation of a cultivatable spirochete from Ixodes ricinus ticks of Switzerland. Curr Microbiol 1983; 8: 123-6. remain undetected and is not apparent until the patient flexes the elbow or supinates the forearm against resistance, manoeuvres which would be impossible to carry out at the time of the fracture. I would surmise that the rupture of the tendon may have occurred at the time of the fracture and remained undetected particularly if at follow up she was not always seen by the same doctor, or that the weakened tendon snapped in the convalescent phase when she was performing shoulder and arm exercises. In either case the tendon would not have ruptured had it not been for the fracture and so can hardly be called spontaneous.

Department of Rheumatology,

Worthing Hospital,

Worthing

\section{Reference}

1 Hanly J G, Urowitz M B. Tendon rupture in systemic lupus erythematosus. Ann Rheum Dis 1986; 45: 349.

SIR, Although it is impossible to disprove Dr Richards' $\vec{\omega}$ comments, we feel that they are unlikely. Our patient $\mathbb{D}$ sustained a minimally displaced fracture which required $\mathbb{D}$ supportive strapping only. She was seen in follow up on four occasions by the orthopaedic and rheumatology $\mathbb{\Phi}^{\circ}$ services before presentation with tendon rupture. This review was in a research clinic setting where musculo $\overrightarrow{0}$ skeletal problems are specifically sought. The patie insisted that muscle swelling did not occur until seven months after the fracture. We feel, therefore, that spontaneous tendon rupture is the most likely diagnosis in this case.

Rheumatic Disease Unit,

Wellesley Hospital,

M B UROWITZ $\Rightarrow$

Toronto,

Canada

\section{Corticosteroids in rheumatoid arthritis}

SIR, I read with interest the recent paper of Byron and Kirwan on the feasibility of conducting a study to determine whether low dose corticosteroids modify the course of rheumatoid arthritis. ${ }^{1}$ The authors solicited the views of your readers regarding the acceptability of long term use of prednisone $(7.5 \mathrm{mg})$ in relation to potential side effects.

An increasing body of evidence suggests that prolonged corticosteroid therapy accelerates the development of atherosclerosis. ${ }^{2}$ Even low doses of corticosteroids may result in significant side effects such as hypertension, hyperlipidaemia, and impaired glucose tolerance. ${ }^{34}$ Each of these adverse effects is a recognised coronary risk factor.
SIR, I read with interest the letter by Hanly and Urowitz 1 on the spontaneous rupture of the long head of biceps tendon in a 35 year old woman with SLE on long term corticosteroid therapy and who had suffered a fracture of the neck of the left humerus some seven months previously. It is perhaps straining our credibility too much to ask us to accept this as spontaneous rupture of the tendon when presumably the cause of the fracture (we are not told) was traumatic in nature. Rupture of the long head of biceps can

\title{
Tendon rupture in systemic lupus erythematosus
}

